\title{
Innovative approaches in technology challenges in the context of industry 4.0
}

\author{
Lucia Knapcikova' ${ }^{1}$ Dragan Peraković ${ }^{2}$
}

Accepted: 2 December 2021 / Published online: 4 January 2022

(C) The Author(s), under exclusive licence to Springer Science+Business Media, LLC, part of Springer Nature 2021

This special issue will provide a venue for publishing the latest research and developments in advances in information, communication, industrial engineering and management areas. Only original and unpublished contributions will be considered under simultaneous review at another conference or journal. The special issue, in particular, welcomes contributions that deal with the various aspects of the Internet of Things, Cloud Computing, Big Data, Artificial Intelligence, Information and communication analysis/Security/e-Forensics, Enterprise information system, Traffic management intelligent infrastructure (road, freight, public transport). In such an ecosystem of interconnected elements and advanced communication between humans and machines, achieving and retaining the required level of security and privacy is a great challenge.

The world of Industry 4.0 is built on the fact that people, machines, equipment, logistics systems and products can communicate and cooperate directly. Everything contributes to total networking. The reason is to use a huge amount of hitherto elusive information to make faster and more correct decisions. Tight interconnection of products, equipment, people increases the efficiency of production machines and equipment, reduces costs and saves resources. Smart tracking and transparent processes provide companies with a constant overview that allows them to respond flexibly and quickly to market changes. The new transformation is based on the new technological approaches that will be made possible by digitization processes.

Lucia Knapcikova

lucia.knapcikova@tuke.sk

Dragan Peraković

dragan.perakovic@fpz.unizg.hr

1 Faculty of Manufacturing Technologies, Technical University of Košice, Košice, Slovakia

2 Faculty of Transport and Traffic Sciences, University of Zagreb, Zagreb, Croatia
These changes will have a direct impact on the operation of the new one's intelligent functions.

This issue features six selected articles of high quality. The first article, with the title "Case study: The Simulation modelling of selected activity in a warehouse operation" deals with the simulation of selected activities in the warehouse. Routine logistics activities are the receipt of the goods, the control of the goods, and the goods' storage in the warehousing system on the side of the entry into the warehouse. On the output side, these are activities such as picking, packing and shipping.

The main goal of the second article, "The Urban Traffic Noise Monitoring System Based on LoRaWAN Technology" are noise and air pollutions. They are among the most important problems and challenges in urban environments. Noise can cause several problems in functioning within urban settlements and may result in various health problems. Continuous monitoring, prevention, and active work on solving these problems focus on research communities, local and national agencies and organizations, and many international organizations. Traffic noise on city roads has been identified as one of the major problems in urban settlements. Fortunately, it can be monitored and controlled to reduce its level and negative effects. One of the most effective and cheapest ways to monitor and control traffic noise is to use wireless sensor networks, IoT technology, and cloud-based architectures.

The third article deals with "A review of optical networking technologies supporting 5G communication infrastructure". The aim is to provide an overview of recent developments of advanced optical networking to provide 5G transport networks and their applications in connecting a huge number of devices in future smart city infrastructures. The implementation of optical technologies in $5 \mathrm{G}$ core networking open numerous questions of how wireless and optical can coexist to provide sophisticated future applications, such as the smart city concept.

The fourth article describes the "Innovative ecosystem for informing the visually impaired person in smart 
shopping environment-InnIoTShop" focusing on conceptual system architecture to deliver InnIoTShop information service to users moving through smart stores. The proposed architecture is based on the IoT concept, and an InnIoTShop service taxonomy has been created for this service.

The fifth article with the title "Innovations and New Possibilities of Vehicle Tracking in Transport and Forwarding" looks on development and innovation in road transport and IT systems implemented in enterprises. The research aims to identify innovations and new possibilities in the field of telematics systems used to identify transportation units in motion.

The sixth article presents "Artificial Intelligence empowered Emails Classifier for Internet of Things based Systems in Industry 4.0" and an effective approach to secure IoT devices from unsolicited emails by using certain AI-based features and clustering in real-time. The main task was to create a new strategy for first filters the unwanted emails from the incoming traffic and then classifying them into spam and phishing for Internet of Things (IoTs) based systems in industry 4.0.

Our big Thank is to Editor-in-Chief Prof. Dr. Imrich Chlamtac and European Alliance for Innovation (EAI) for their great support and guidance during the entire process. We are also thankful to the reviewers for their efforts and all suggestions and comments in reviewing the manuscripts', and we believe in strong, fruitful cooperation in the future.

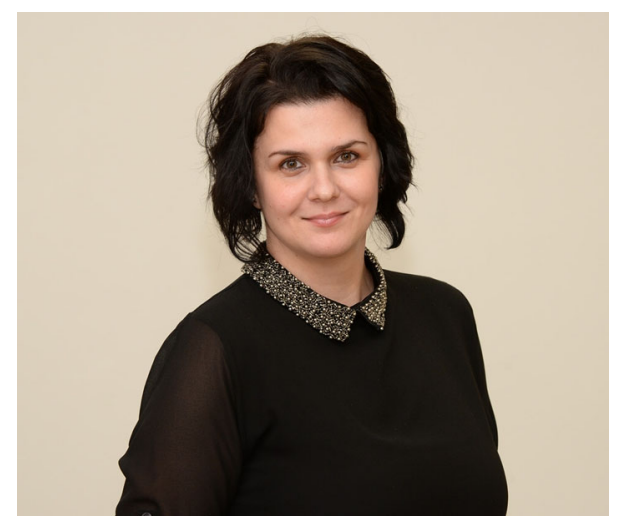

Assoc. Prof. Eng. MSc. Lucia Knapcikova, Ph.D.

Lucia Knapcikova is Vice-Dean for International Relations and Mobility at the Faculty of Manufacturing Technologies (FMT) of the Technical University of Košice. In
2017 she completed her Habilitation for Associate Professor at the FMT in the field "Manufacturing Technologies". In 2011 she completed her PhD study at the Faculty mentioned above. Lucia Knapcikova is the author of more than 215 scientific papers in Slovakia and abroad, and she is the owner of 6 utility models.

She participated in several international research projects, mainly in Germany. A most important project is H2020 Less Than Wagon Load (Project duration 2017-2020) in collaboration with Belgium, Germany, Netherland, Italy and Slovakia, where she is the Faculty project coordinator. The project aims to develop a SMART specialised logistics cluster for the chemical industry in the Port of Antwerp to shift transport volumes from road to rail freight. She has participated in project EUROSTARS (BRIDGE2ERA Program) with the collaboration of the Technical University of Applied Sciences in Wildau (TH Wildau), Germany. The aim of the project is Industry 4.0 strategic orientation between universities and SME. Lucia Knapcikova is from 01.10.2021 principal investigator of an international project with the collaboration of TU Graz (Austria) and research institute Pro2Future (Austria). The scheme is Action Austria-Slovakia title of the project talks about Sustainable Production Systems-Enhancing Science and Education.

She lectured at the universities in Germany (TH Wildau), Czech Republic (TU Liberec) and Croatia (J.J. Strossmayer University of Osijek, Mechanical Engineering Faculty in Slavonski Brod). Her area of interest includes SMART technologies, SMART materials, applications possibilities directly in the industry. In 2018, she was awarded in the category "Personality of Science and Technology under 35 years". In support of the development of science and technology, the Ministry of Education, Science, Research and Sport of the Slovak Republic and the recognition of the exceptional achievements in this field, awarded the Science and Technology Awards-the highest award in science and technology, for the year 2018.

She is a member of European Alliance for Innovation, Belgium (www.eai.eu), TEAM Society in Croatia and an active member of the Editorial Board of Acta Tecnología Journal (Slovakia), SAR Journal (Serbia). She works as Guest Editor in the indexed journal (CC Journal) Wireless Networks-WINET. She is a responsible person for organizing of International conferences under EAI organization- MMS 2022, MMS 2021, MMS 2020 and previously MMS2019, MMS2018, MMS2017, MMS2016 and EAI Fabulous 2022 and EAI Fabulous 2021.

Dragan Peraković received B.Sc. degree in 1995, M.Sc. degree in 2003, and Ph.D. in 2005, all at the University of Zagreb, Croatia, EU. Dragan is Head of the Department for Information and Communication Traffic and Head of Chair 


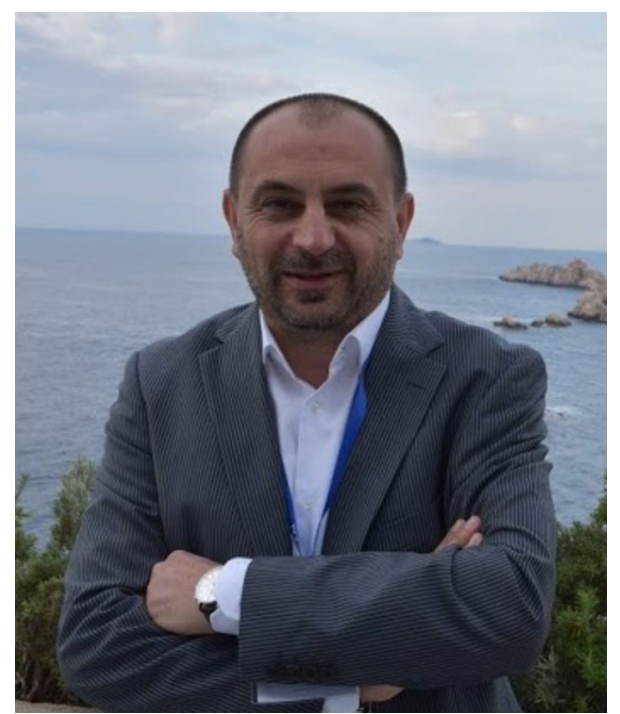

Prof. Dragan Peraković, Ph.D.

of Information Communication Systems and Services Management, all at the Faculty of Transport and Traffic Sciences, University of Zagreb, where he is currently a full professor. Dragan is visiting professor at University of Mostar, Faculty of Science and Education Sciences, Mostar/Bosnia and Herzegovina.

Area of scientific interests and activities is: modelling of innovative communication ecosystems in the environment of the transport system (ITS) and Industry 4.0; AI \& ML in cybersecurity, DDoS, Internet of Things; AI in e-forensic of communication ecosystems (terminal devices/services); design and development of new innovative services and modules.

Dragan is an author/co-author of more than 140 scientific papers in indexed journals and proceedings of international conferences and 14 chapters in international scientific books. Additionally, he is co-editor of more than 15 edited indexed books and proceedings. He participated in the work of several international scientific projects and research \& development studies. Dragan is an MC member in COST action CA17124-Digital forensics: evidence analysis via intelligent systems and practices (DigForAsp) \& MC Substitute member in COST action CA15127Resilient communication services protecting end-user applications from disaster-based failures (RECODIS).

Dragan is a member of TM Forum (USA), IEEE (USA), DAAAM International (EU/Austria), SDIWC (Hong Kong), EAI-European Alliance for Innovation (EU), Association for promotion of innovative technologies InnovativeFET (EU/Croatia), International Association for Technological Development and Innovations (Ukraine), International Telecommunication Society-ITS (EU). Dragan is President of the Croatian Chamber of Transport Engineers since 2020. Dragan is in the top $0.1 \%$ of individuals who achieved the greatest success on the EAI rankings in calendar 2019 among the entire EAI community (EAI Fellows Class 2020).

Dragan is the first Chief Editor of the International Journal of Cyber-Security and Digital Forensics (IJCSDF), Hong Kong, and Guest Editor in a few SI in WoS indexed journals. Dragan is a member of the Steering Committee and General Chair at EAI MMS and EAI Fabulous conference series, and a member of big numbers of Program/ Scientific/Organization Committee of International Scientific Conference, worldwide.

Publisher's Note Springer Nature remains neutral with regard to jurisdictional claims in published maps and institutional affiliations. 